\title{
Learning and retention in cats with lesions in reticular formation'
}

\author{
Kao Liang Chow, STANFORD UNIVERSITY SCHOOL OF MEDICINE \\ Walter Randall, DUKE UNIVERSITY
}

\begin{abstract}
Cats with lesions in the reticular formation at the level of the superior colliculus and red nucleus learned conditioned avoidance responses and visual discriminations as well as normal cats. In cats with preoperative training, the midbrain surgery had little or no effect on postoperative performance. Cats with lesions in the midline nuclei of the dorsal thalamus exhibited a postoperative loss of a previously learned visual discrimination and required more trials to relearn. All cats had normal electrocorticogram (ECG) (awake and sleep), and exhibited normal conditioned ECG potentials.
\end{abstract}

\section{Introduction}

A large body of literature supports the generalization that the midbrain reticular formation participates critically as the anatomical substrate of consciousness, sleep, attention, and emotion (Magoun, 1963; Lindsley, 1960). Several authors also suggest that the reticular formation plays a central role in learning and memory (Gastaut, 1958; Hernandez-Peon \& Brust-Carmona, 1961). Some of the evidence for considering the reticular formation as important in learning and memory are the progressive alterations in electropotentials obtained from the midbrain reticular formation during various conditioning procedures. However, such alterations have not been consistenly found (Morrell, 1961). The present report is an attempt to assess the learning capability and the ECG of cats with lesions in the midbrain reticular formation and in the midline thalamus.

\section{Method}

Eleven cats were subjected to stereotaxic surgery, seven receiving lesions confined to the midbrain, two receiving lesions restricted to midline thalamus and two receiving both the thalamic and midbrain lesions. The stereotaxic lesions in the reticular formation were made in two to four stages, with 1-3 months recovery time between stages. After the surgery, as well as before in most cases, the cats learned conditioned avoidance responses and food-rewarded visual discriminations. At the completion of these learning procedures, usually 3-4 months after the last surgery, epidural cortical electrodes were implanted in various areas of the cerebrum for ECG recordings. The formation of conditioned ECG potentials, the surgical procedure, and the histological data will be reported elsewhere.

Nine of the eleven cats were trained both before and after the surgery; the other two cats had only postoperative training. All cats learned two conditioned avoidance responses and two or three food-rewarded visual discriminations. For the conditioned avoidance responses the conditioned stimulus for the first task was a buzzer

and for the second flickering light (6-10 per second), with the apparatus (shuttle box) and procedure the same as those described by Chow, Dement \& John (1957). For the visual discriminations, a Y-shaped Yerkes box was used with the usual training procedure as previously described (Chow, Dement \& Mitchell, 1959). A black vs. white discrimination was used initially to familiarize the naive cats and to adapt the operated cats to the learning situation. The main tasks in the Yerkes box consisted of (1) a black circle vs. a black square on white backgrounds, and (2) a black vertical bar vs. a black horizontal bar on white backgrounds. Ten to 20 trials were given each day for both the conditioned avoidance response and visual discrimination training, with criterion for learning selected as $90 \%$ correct in 20 trials.

\section{Results}

The transection of the reticular formation was complete in seven cats, including the two with additional thalamic lesions. The prefix of RF was used to designate these animals in the tables. Cats RFA and RF11 had only partial lesion of the reticular formation. The midline thalamus was completely destroyed in all four cats (T6, T7, RFC, RF6).

Tables 1 and 2 present the learning scores for all cats. In Table 1 the learning scores for cats without preoperative training are presented; all these scores are within the normal range (c. f. Randall, 1964). Table 2 shows the results for the cats with both pre-and postoperative learning scores. On the conditioned avoidance problem, cats either retained or relearned rapidly. On the visual discrimination, the cats with only the midbrain lesion exhibited retention or rapid relearning. But the four cats

Table 1. Learning scores of cats after midbrain and midline thalamic lesions (number of trials to criterion, excluding criterion trials).

Conditioned Avoidance

\begin{tabular}{|c|c|c|c|c|}
\hline Cat & Buzzer & Flicker & $\begin{array}{l}\text { Square vs. } \\
\text { Circle } \\
\end{array}$ & $\begin{array}{l}\text { Vertical vs } \\
\text { Horizontal }\end{array}$ \\
\hline RF3 & 60 & 60 & 120 & 60 \\
\hline R F5 & 60 & 60 & 30 & 50 \\
\hline R Fl2 & - & - & - & 60 \\
\hline R Fl4 & - & - & - & 100 \\
\hline T6 & - & - & - & 120 \\
\hline RFC & - & - & - & 200 \\
\hline RFA & - & - & - & 80 \\
\hline
\end{tabular}


Table 2. Pre- and postoperative learning scores of cats with midbrain and midline thalamic lesions (number of trials to criterion, excluding criterion trials). $\underline{\text { Conditioned Avoidance }}$

Cat

$$
\text { (after buzzer training) }
$$$$
\underline{\text { Pre }}
$$

$\underline{\text { Post }}$

RFl2 80

RFll

RFA

$$
100
$$

R F13

$$
140
$$

40

R F6

T6

$\mathrm{T} 7$

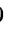

0

10

20

100

0

20

40

50
Square vs. Circle (after brightness training)

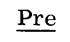

$\underline{\text { Post }}$

180

200

140

220

120

160

120

120
Visual Discriminations

with midline thalamic lesions required more trials than preoperatively to relearn the visual discrimination. These four cats with midline thalamic lesions (two of which also possessed the midbrain lesion) were not acquainted with the Yerkes-box problem after the surgery: They failed to follow the experimenter to the location and to operate the doors to the food as they did preoperatively.

\section{Diseussion}

Our results show that cats with reticular formation lesions learn conditioned avoidance responses and visual discriminations as well as normal cats, thus confirming Adametz's informal observations (1959). Furthermore, no abnormalities in the ECG were present in any of these cats, which is consistent with a report on dogs without midbrains and caudal thalami (Batsel, 1960). It is apparent that there are two ways to prevent the acute effects (loss of consciousness and sleep-like ECG) of midbrain lesions: Either do the lesion in stages (Adametz), or be thorough with the postoperative care (Batsel).

The failure of lesions of the midbrain reticular formation to disrupt learning does not imply that the reticular formation plays no roles in normal animals. The inherent limitations of the ablation method preclude any conclusions in this regard. The data on the midbrainlesioned cats with both pre- and postoperative training indicate perfect retention or relearning in better or normal time for both the conditioned avoidance problems and the visual discrimination. Loss of a learned habit with relearning is the general finding after lesions in central nervous system. (See e.g. review by Morgan, 1951). Thus again no unique role may be attributed to the midbrain reticular formation.
In this study the first problem in both the shuttle box and the Yerkes box were not considered in the evaluation of the data. The buzzer-avoidance problem and black vs. white visual discrimination provided the essential controls for such non-specific influences on the learning scores as postural, motor or perceptual deficits, and motivational or emotional differences.

\section{References}

ADAMETZ, JOHN H. Rate of recovery of functioning in cats with rostral reticular lesions. J. Neurosurg., $1959,16,85-98$.

BATSEL, H. L. Electroencephalographic synchronization and desynchronization in the chronic "cerveau isole" of the dog. EEG clin. Neurophysiol., 1960, 12, 421-430.

CHOW, K. L., DEMENT, W. C., \& JOHN, E. R. Conditioned electrographic potentials and behavioral avoidance response in cat. J. Neurophysiol., 1957, 20, 482-493.

CHOW, K. L., DEMENT, W. C., \& MITCHELL,S. A. Jr. Effects of lesions of the rostral thalamus on brain waves and behavior in cats. EEG clin. Neurophysiol., $1959,11,107-120$.

GAUSTAUT, $\mathrm{H}$. The role of the reticular formation in establishing conditioned reactions. In H. H. Jasper, L. D. Proctor, R. S. Knighton, W. C. Noshay, \& R. T. Costello (Eds.), Reticular formation of the b r a i n. Boston: Little Brown \& Co., 1958, Pp. 561-579. HERNÁNDEZ-PEÓN, R., \& BRUST-CARMONA, H. Functional role of subcortical structures in habituation and conditioning. In J. F. Delafresnaye (Ed.), Brain mechanisms and learning. Oxford: Blackwell, 1961. Pp. 393-412.

LINDSLEY, D. B. Attention, consciousness, sleep and wakefulness. In J. Field (Ed.), Handbook of physiology, neurophysiology, Vol. III. Washington, D. C.: Am. Physiol. Soc., 1960. Pp. 1553-1593.

MAGOUN, H.W. The waking bra in. (2nd ed.) Charles C. Thomas, 1963.

MORGAN, C. T. The psychophysiology of learning. In S. S. Stevens (Ed.), Handbook of experimental psychology. New York: John Wiley \& Sons, 1951. Pp. 758-788.

MORRELL, F. Electrophysiological contributions to the neural basis of learning Physiol. Rev., 1961, 41, 443-494.

RANDALL, W. Generalization after frequency discrimination in cats with central nervous system lesions. In D. Mostofsky (Ed.), Stimulus generalization. In press. Stanford University Press. 1964.

\section{Note}

1. The present study was supported in part by a Research Career Award (NB-K6-18, 512) to the first author, and Research Grant B-3816-03 from the NINDB, National Institutes of Health. 